\title{
EVALUATION OF THE COHESIVE PROPERTIES OF SBS- MODIFIED BINDERS AT LOW TEMPERATURES
}

\author{
Baha Vural KÖK ${ }^{1 *}$, Yunus ERKUŞ ${ }^{1}$, Mehmet YILMAZ ${ }^{1}$
}

\begin{abstract}
The durability, fatigue resistance, and low-temperature behavior of asphalt layers are greatly affected by the properties of bitumen. Therefore, the composition of bitumen is frequently modified to improve the performance of asphalt mixtures. Styrene-butadiene-styrene (SBS) has been the most often used additive recently. Researchers are trying to improve the cohesive and adhesive properties of binders by such polymer-based additives. In this study, 160/220 penetration grade bitumen and Kraton D 1101 SBS were used. The present study contains a new evaluation for determining the cohesive behavior of SBS-modified binders at $-1{ }^{\circ} \mathrm{C},-3^{\circ} \mathrm{C}$, and $-5^{\circ} \mathrm{C}$. The results of this evaluation were compared to conventional and rheological test results. Penetration, softening point, viscosity, dynamic shear rheometer, and bending beam rheometer tests were therefore conducted. Finally, the results of a low-temperature tensile test were found to be consistent with the results of the other tests; hence, they also confirm the cohesive behavior of SBS-modified binders at low temperatures.
\end{abstract}

\section{Address}

1 Department of Civil Engineering, Firat University, Elazığ/Turkey

* Corresponding author: bvural@firat.edu.tr

\section{Key words}

- Bitumen,

- Cohesion,

- SBS,

- Modification,

- Low temperature.

\section{INTRODUCTION}

The resistance of bituminous mixtures to thermal cracking and permanent deformations needs to be improved due to severe environmental conditions and increasing vehicle loads. The satisfactory performance of bituminous mixtures can be achieved by controlling their adhesive and cohesive properties (Adedeji, A. et al., 1996). A bituminous pavement can be damaged because of the structure of the binder or binder-aggregate interface (Zhang, H. et al., 2016). Adhesive failure is specifically defined as a decrease in the adhesion at the aggregate-bitumen interface in the case of water, while cohesive deterioration is defined as the secession of molecules from the bitumen film (Hicks, R. G. 1991). It is necessary to control the adhesive and cohesive properties of bitumen to ensure the durability of asphalt mixtures. Therefore, the use of different additives to improve the adhesive and cohesive properties of bitumen has been undertaken for quite a long time (Aksoy, A. et al., 2005; Syroezhko, A. M. et al., 2011; Komačka, J. et al., 2019; Oliviero Rossi, C. et al., 2017; Tarefder, R. A. et al., 2010).

The adhesive force between the bitumen and aggregates in bituminous mixtures is one of the variables affecting stripping problems, creep behavior, and fatigue fractures. The use of $\mathrm{Nano}_{-} \mathrm{TiO}_{2}$ has increased the total free surface energy of the bitumen; thus the quantity of energy required to form a cohesive crack in the binder has increased (Azarhoosh, A. et al., 2018). The modification of bituminous binders with polymer additives generally enhances the properties of asphalt mixtures such as rutting, thermal cracks, and fatigue life (Lu, X. 2003). Among these polymer additives, styrene-butadiene-styrene (SBS) is one of the most widely used ones. With their excellent chain structure in bituminous binders in terms of low-temperature thermal cracks and high-temperature permanent deformations, SBS-modified bituminous mixtures perform better than other mixtures (Polacco, G. et al., 2001). 


\section{ADHESIVE- COHESIVE TEST METHODS}

Because the failure mechanism is closely related to the adhesive-cohesive concept, researchers have been trying to determine the relationship between aggregates and bitumen, as well as the bitumen itself. It has been concluded that the interfacial interaction between bitumen and aggregates is a physical-chemical process and can be quantitatively evaluated by rheological methods and interfacial mechanical tests (Guo, M. et al., 2018). Paliukaite et al. (2016) compared various test methods to determine the properties of bitumen adhesion. These tests were identified as the European standards (rolling-bottle test, detachment in boiling water, and static water storage) and the Lithuanian standard (boiling water test). The experiments revealed the relationship between bitumen and aggregates with several deficits such as the predicted image of a pavement. The best experimental results were obtained after 6 hours from the rolling-bottle test method (Paliukaitè, M. et al., 2016).

Zolotaryov et al. (2016) attempted to predict the shear strength and resistance of the rutting of an asphalt pavement by the cohesive property of its bituminous binders. The cohesion of the bitumen was determined by the shear stress applied to the binder in the shape of a disk and a thickness of 200 microns. The cohesion of the binder was defined as the maximum point of the curves obtained from the temperature-cohesion plot, and the temperature of this peak point represented the transition from an elastic-viscoplastic state to a fragile state (Zolotaryov, V. et al., 2016). Maliar (2016) investigated the cohesive properties of the binders in various structures. A test method, which consisted of elastic strips glued with the bitumen and separated from them by pulling, was used in the study. It was determined that the fracture energy increased linearly after the bitumen had a film thickness of 200 microns. It has been determined that binders having a higher level of viscosity have higher cohesive resistance (Maliar, V. 2016). Canestrari et al. (2010) investigated the impact of water on the adhesive and cohesive properties of bituminous mixtures. The study was conducted to evaluate the tensile strength of distinct asphalt mixture combinations and the impact of water at two distinct temperatures. It was determined that while there was deterioration in the cohesion of the crumb rubber $(\mathrm{CR})$ modified binders and Elvaloy modified binders, there were adhesive deteriorations in the SBS-modified binders. The adhesive and cohesive failures occurred for porphyric and limestone aggregates, respectively (Canestrari, F. et al., 2010). The adhesive fracture energy between the bitumen and aggregates (marble, limestone, and granite) was measured using the peel test. The basic aggregates (marble and limestone) provided better water resistance than the acidic aggregates (granite) Marble aggregate is chemically parallel to limestone aggregate, but it demonstrates better water resistance owing to its lesser porosity. The SBS was found to have a significant effect on improving the water resistance (Cui, S. 2014). Omar et al. (2016) determined the adhesive strengths of original and aged binders containing various additives by using the tensile test. According to the results, the adhesive strength, which was measured by a tensile test, was found to have a high correlation with the values of the viscosity and activation energy (Omar, H. A. et al., 2016). Wistuba et al. (2012) used laboratory test techniques to determine the adhesive properties of bitumen. According to the test results, the effect of a variety of bitumen on the adhesive behavior was found to be less than the effect of the variety of aggregates (Wistuba, M. P. et al., 2012). Huang et al. (2016) devised a new adhesion test to investigate the factors that affect adhesive strength, especially the pull ratio and the thickness of asphalt film. The thickness of the film and loading speed were tested with the same performance grade asphalt (PG 64-22) under different combinations. The results revealed that the tensile strength values decreased with the increase in the thickness of the film, while the tensile strength values increased with the increase in the loading speed when the thickness of the film was kept constant (Huang, W. et al., 2016). Wei et al. (2015) tried to determine the low-temperature performance of SBS+PPA-modified bitumen using the force ductility test at a temperature of $5^{\circ} \mathrm{C}$ and a pull speed of $50 \mathrm{~mm} / \mathrm{min}$. They reported that the work of the fracture and toughness rate increased with the increase in the SBS content. After aging the binder, the absorbed energy and the toughness rate of the SBS-modified bitumen lowered (Wei, Y. et al., 2015). The modification of pure bitumen with $3 \mathrm{wt} \%, 6 \mathrm{wt} \%$, and $10 \mathrm{wt} \%$ SBS additions increased the cohesion values by $2.5,3.5$, and 4.1 times, respectively. Finally, it was found that the shear strength determined by applying torsional strength has a good compatibility with the bitumen cohesion values (Zolotaryov, V. et al., 2016).

Standard ductility, force ductility, a pendulum, and some new tests were used to assess the cohesive properties of the bituminous binders. The extensively used force ductility test was conducted at a temperature higher than $5^{\circ} \mathrm{C}$ in water. This study aims to assess the effect of a low temperature on cohesive properties. Therefore, the cohesive properties of pure and SBS-modified binders were determined at $-1{ }^{\circ} \mathrm{C},-3^{\circ} \mathrm{C}$, and $-5^{\circ} \mathrm{C}$ by new evaluations. The results of the low-temperature tensile test were then compared with those of the conventional and rheological tests, and the suitability of the new evaluation was examined.

\section{MATERIALS AND METHODS}

Bitumen (B160/220), which was obtained from the TUPRAS Refinery in Turkey, was utilized as a pure binder in the study. The properties of the pure bitumen are given in Table 1. The Kraton D-1101 SBS polymer was utilized in this study. SBS has a styrene/rubber ratio of 31/69 and a tensile strength of 4600 psi. Its elongation at break value is $880 \%$.

\section{Tab. 1 Properties of the pure binder}

\begin{tabular}{lll}
\hline Properties & Standard & B 160/220 \\
Penetration $(0.1 \mathrm{~mm}), 100 \mathrm{~g}, 5 \mathrm{~s}$ & ASTM D5 & 206.3 \\
Softening point $\left({ }^{\circ} \mathrm{C}\right)$ & ASTM D36 & 42.1 \\
Penetration index $(\mathrm{PI})$ & & 1.038 \\
Specific weight $\left(\mathrm{g} / \mathrm{cm}^{3}\right)$ & & 1.019 \\
Viscosity $\left(\mathrm{cP}, 135^{\circ} \mathrm{C}\right)$ & ASTM D4402 & 262.5 \\
Viscosity $\left(\mathrm{cP}, 165^{\circ} \mathrm{C}\right)$ & ASTM D4402 & 100 \\
\hline
\end{tabular}

SBS was used in four different ratios, i.e., $2 \%$ (2B), 4\% (4B), $6 \%$ (6B), and $8 \%(8 \mathrm{~B})$, by the weight of the bitumen. The SBS was added to the bitumen at $170^{\circ} \mathrm{C}$ and $2000 \mathrm{rpm}$ for 30 minutes as its mixing conditions. Also, the same mixing process was applied to the pure binder to provide a valid comparison.

The pure and modified binders were first subjected to penetration and softening point experiments; the Penetration Index (PI) values, which are a measure of the temperature sensitivity of the binders, were calculated using these two values. Then, rotational viscosities at $135^{\circ} \mathrm{C}$ and $165^{\circ} \mathrm{C}$ were determined; the resistance to flow was then measured. The rutting parameters of the binders were determined by the dynamic shear rheometer (DSR) test at $52^{\circ} \mathrm{C}, 58^{\circ} \mathrm{C}, 64^{\circ} \mathrm{C}, 70^{\circ} \mathrm{C}$, and $76^{\circ} \mathrm{C}$. The bending beam rheometer (BBR) test was applied at $-10^{\circ} \mathrm{C}$ to assess the low-temperature behavior of the binders. Finally, a tensile test was carried out at $-1^{\circ} \mathrm{C},-3^{\circ} \mathrm{C}$, and $-5^{\circ} \mathrm{C}$ with a new experimental setup. 


\section{TESTS AND RESULTS}

\subsection{Conventional Tests}

The penetration test is carried out to evaluate the hardness and consistency of bituminous binders. This test was conducted following the ASTM D5 standard. The test classified the bituminous binders into standard penetration ranges. The softening point method is an experiment to measure the sensitivity of bituminous binders to the temperature. The softening point value of the bituminous binders is determined with a ring and ball according to ASTM D36. The penetration index value, as determined by the penetration and softening point values, indicates the reaction of the bituminous binders to changes in temperature. It is essential to know the penetration index value to estimate the behavior of bituminous mixtures in an application. The rotational viscometer (RV) test determines the workability of bituminous mixtures during the mixing and compaction processes. The test is conducted according to the ASTM D4402 standard. In this study, a Brookfield DVIII rotational viscometer was used to determine the viscosity of pure and SBS-modified binders. The results obtained from the penetration, softening point, and viscosity tests are given in Table 2 .

Tab. 2 Conventional test results

\begin{tabular}{lccccc}
\hline Tests & Base & 2B & $4 \mathrm{~B}$ & $6 \mathrm{~B}$ & $8 \mathrm{~B}$ \\
\hline Penetration & 206.3 & 146.7 & 100.8 & 80.3 & 69.8 \\
Softening point & 42.1 & 46.7 & 53.7 & 64.5 & 71.2 \\
Penetration Index (PI) & 1.03 & 1.07 & 1.73 & 3.36 & 3.85 \\
Viscosity $\left(\mathrm{cP}, 135^{\circ} \mathrm{C}\right)$ & 262.5 & 562.5 & 1125 & 2150 & 3513 \\
Viscosity $\left(\mathrm{cP}, 165^{\circ} \mathrm{C}\right)$ & 100 & 175 & 325 & 650 & 1038 \\
\hline
\end{tabular}

The penetration values were observed to decrease steadily as the SBS content increased. This decrease rapidly occurs by modifying the SBS composition with a small amount of pure binder (2\%); thus, the effect on the drop in penetration is reduced by the increase in the SBS content. The 2B, 4B, 6B and 8B binders give $29.3 \%, 51.1 \%$, $60 \%$ and $67.5 \%$ lower penetration values than the pure binder, respectively. When $4 \%$ SBS is used with a pure binder, the hardness of the binder is doubled.

The addition of SBS linearly increases the softening point values of the binder. The softening point values of pure bitumen increase with the $2 \mathrm{~B}, 4 \mathrm{~B}, 6 \mathrm{~B}$, and $8 \mathrm{~B}$ by $10.6 \%, 27.8 \%, 53.3 \%$, and $68.9 \%$, respectively. It can be seen that SBS has a great effect on both the softening point and penetration value.

The penetration index (PI), which is determined by using the softening point and penetration values, are used to evaluate the temperature sensitivity of the binders. The high penetration index of the binders indicates that the sensitivity to temperature is low. It appears that the addition of SBS to the pure binder, particularly an addition of more than $4 \%$, considerably reduces its sensitivity to heat. The PI values of the $6 \mathrm{~B}$ and $8 \mathrm{~B}$ binders are close to each other. There is a significant difference between $4 \mathrm{~B}$ and $6 \mathrm{~B}$ in terms of temperature sensitivity, but this effect decreases after the addition of a $6 \%$ SBS content. According to the PI results, it can be said that a high ratio of SBS-modified binder will perform well in terms of high-temperature permanent deformations and low-temperature cracks.

The viscosity values increase exponentially with an increase in the additive content at temperatures of $135^{\circ} \mathrm{C}$ and $165^{\circ} \mathrm{C}$. In other words, a high proportion of the SBS content is more effective for an increase of viscosity. The addition of $2 \%, 4 \%, 6 \%$, and $8 \%$ SBS at $135^{\circ} \mathrm{C}$ to the pure binder increased the viscosity by $2.1,4.2,8.2$, and 13.3 times, respectively. The high viscosity results indicate resistance to permanent deformations at high air temperatures. However, in terms of workability, the viscosity at $135^{\circ} \mathrm{C}$ should not exceed $3000 \mathrm{cP}$. The addition of $8 \%$ SBS to the pure bitumen increases the viscosity to $3513 \mathrm{cP}$. The SBS content corresponding to $3000 \mathrm{cP}$ viscosity is found to be $7.3 \%$.

\subsection{Rheological Tests}

The dynamic shear rheometer (DSR) test characterizes the rheological features of the bitumen at medium and high temperatures. The DSR test was carried out according to the AASHTO TP5 standard. The complex shear modulus $\left(\mathrm{G}^{*}\right)$ and the phase angle $(\delta)$, which are the essential viscoelastic parameters of the binders, were obtained from the test. In this study, the rheological tests were performed using a Bohlin DSRII rheometer under controlled-stress conditions at five different temperatures and $1.59 \mathrm{~Hz}$ of frequency using a plate with a diameter of $25 \mathrm{~mm}$ and a gap opening of $1 \mathrm{~mm}$.

The $\mathrm{G}^{*} / \sin \delta$ values obtained at different temperatures are given in Fig.1. With the increase in the SBS content, the rutting parameters increase exponentially. The rutting parameter of the 8B binder is higher than the pure binder by $13,15,16,18$, and 19 times at $52^{\circ} \mathrm{C}$, $58^{\circ} \mathrm{C}, 64^{\circ} \mathrm{C}, 70^{\circ} \mathrm{C}$, and $76^{\circ} \mathrm{C}$, respectively. The high-temperature performance levels of the binders are evaluated as PG-58 for the pure binder, PG-64 for the $2 \mathrm{~B}$ binder, $\mathrm{PG}-70$ for the $4 \mathrm{~B}$ binder, $\mathrm{PG}-76$ for the $6 \mathrm{~B}$ binder, and $\mathrm{PG}-82$ for the $8 \mathrm{~B}$ binder.

The bending beam rheometer method gives the measure of the stiffness and relaxation features of bituminous binders at low temperatures. The results reveal the ability of bituminous binders to resist low-temperature cracking (Marasteanu, M. O. et al., 2004). The test was performed according to the AASHTO TP1 standard. The creep stiffness ( $\mathrm{St}$ ) and creep ratio (m-value) were calculated using the deformations that occur at a specific time (60 seconds) of loading. The loading during the experiment reveals that the thermal stresses in the pavement occurred at very low temperatures. The flexible behavior at low temperatures requires a low creep stiffness with high creep ratio values. Hence, the " $\mu$ " value is obtained by dividing the creep stiffness by the m-value for a more realistic evaluation (Liu, S. et al., 2009). The small value of " $\mu$ " is desirable for elastic behavior at low temperatures. The creep stiffness $(\mathrm{St})$ and $\mathrm{m}$-value parameters of the binders were determined at $-10^{\circ} \mathrm{C}$. Fig. 2 shows the changes in the deformation, stiffness, and m-value by the SBS content. While the deformation decreases, the stiffness values increase with the increase in the SBS content. Specifically, a decrease in deformation and an

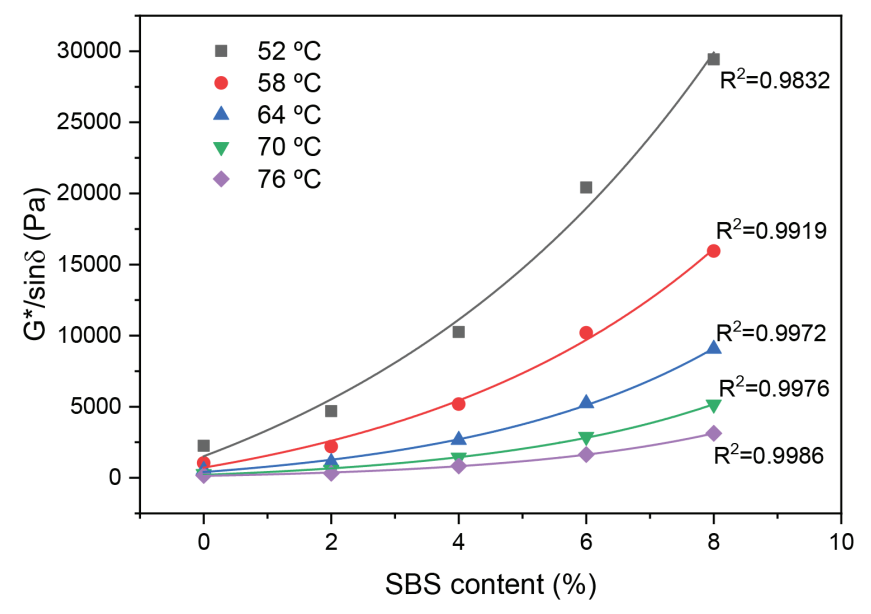

Fig. 1 Relation of SBS content $-G^{*} /$ sin $\delta$ at different temperatures. 

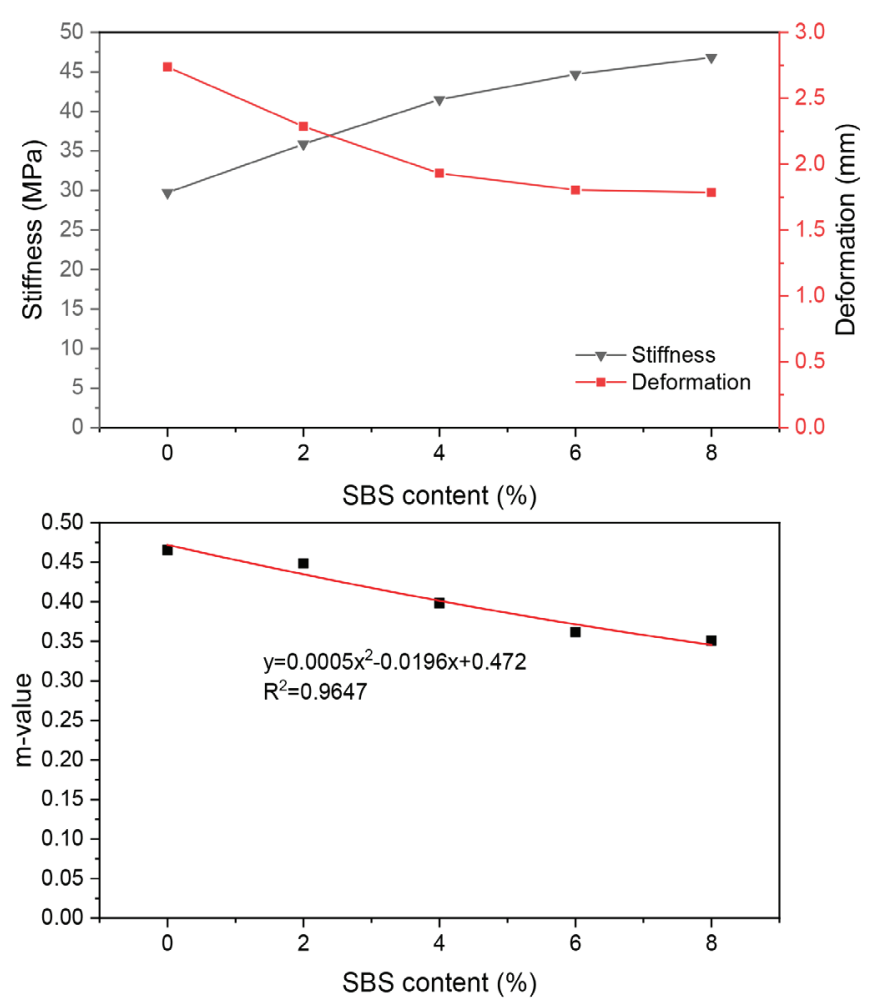

Fig. 2 SBS content and stiffness - deformation relation.

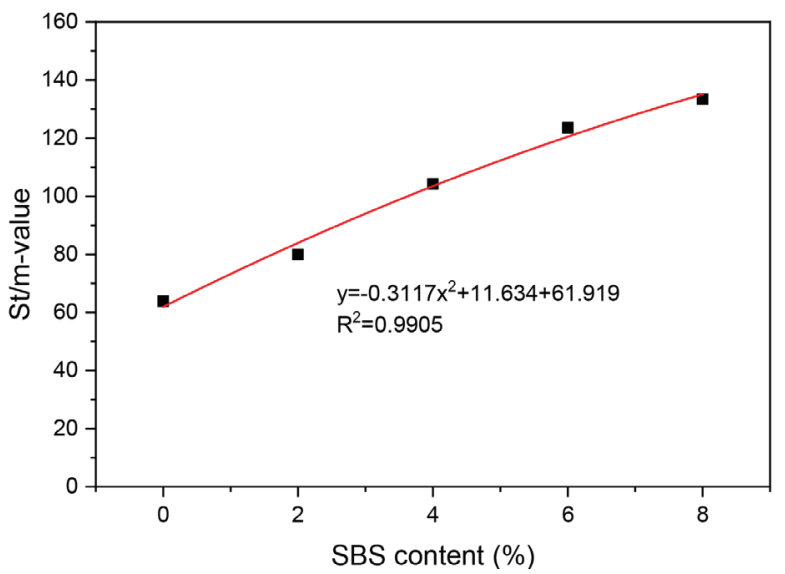

Fig. $3 S B S$ content and St/m-value relation.

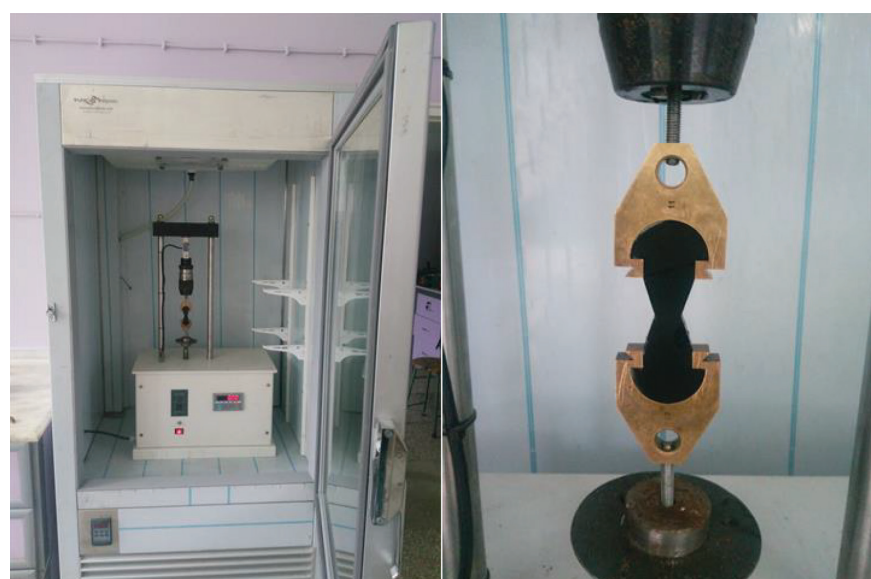

Fig. 4 Low temperature tensile test apparatus. increase in stiffness occur rapidly up to a $4 \%$ SBS content. The $2 \mathrm{~B}$, $4 \mathrm{~B}, 6 \mathrm{~B}$, and $8 \mathrm{~B}$ increase the creep stiffness of the pure binder by $20 \%$, $39 \%, 50 \%$, and $57 \%$, respectively.

To ensure a good low-temperature performance, the binder is expected to have high m-values and low creep stiffness. Fig. 3 shows the change in the SBS content and the " $\mu$ " values. As can be seen, the $\mu$ values constantly increase with the increase in the additive content. However, this rise slows down after an SBS content of $6 \%$. This means that the hardening effect of SBS starts to reach saturation after a content of $6 \%$.

\subsection{Low-Temperature Tensile Test}

In this study, a new experimental setup was prepared to evaluate the cohesive properties of binders at low temperatures (Fig.4). The conventional and force ductility tests used to evaluate the cohesive features of bitumen were carried out at $5^{\circ} \mathrm{C}, 20^{\circ} \mathrm{C}$, and $25^{\circ} \mathrm{C}$ temperatures, while the sample loading rate was $50 \mathrm{~mm} / \mathrm{min}$. The new evaluation involves examining the cohesive properties of the binder at low loading rates and temperatures below $0^{\circ} \mathrm{C}$. In this test method, the binders were poured into a standard ductility mold $(75 \mathrm{~mm}$ length, $10 \mathrm{~mm}$ width with a minimum cross-section of $10 \mathrm{~mm}$ ) and subjected to a tensile force. The test was conducted with the loading rates of 5 and $10 \mathrm{~mm} / \mathrm{min}$ at temperatures of $-1{ }^{\circ} \mathrm{C},-3^{\circ} \mathrm{C}$, and $-5^{\circ} \mathrm{C}$.

It was observed in this study that binders with an SBS content of over $8 \%$ separated without much elongation at a tensile speed of a $10 \mathrm{~mm} / \mathrm{min}$. Fig. 5 shows the post-test views of the SBS-modified binders at a tensile speed of $10 \mathrm{~mm} / \mathrm{min}$ at $-5^{\circ} \mathrm{C}$.

The SBS-modified binders separated without much displacement at the tensile speed of $10 \mathrm{~mm} / \mathrm{min}$, and there was no recovery after

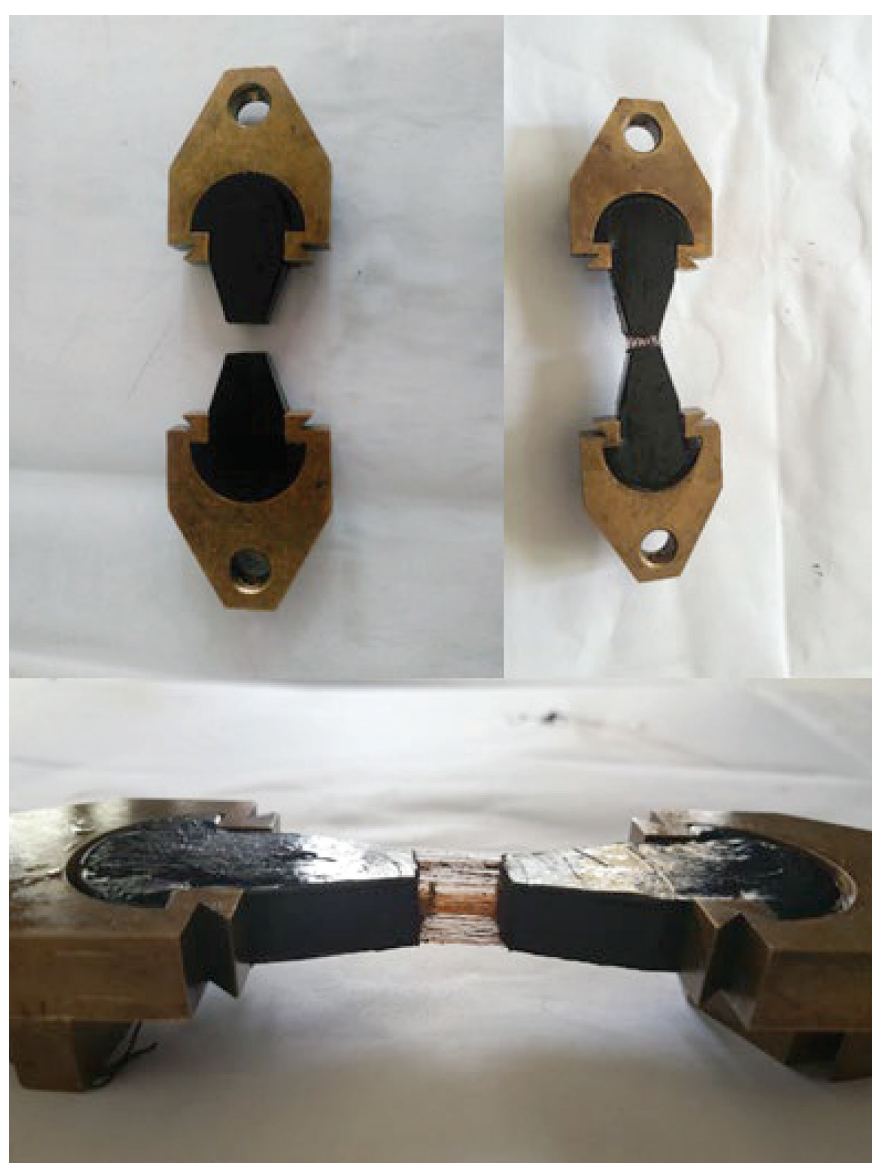

Fig. 5 Appearance of SBS-modified binders after experiment. 


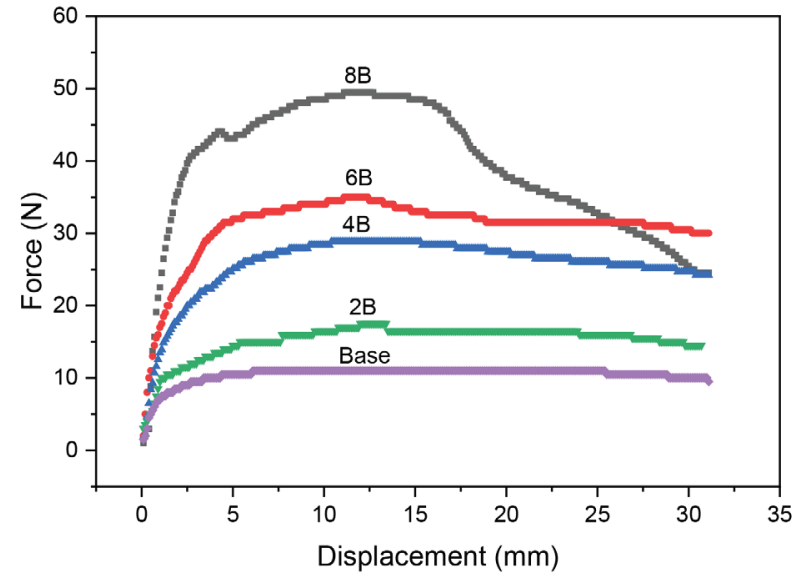

Fig. 6 Force-displacement relation of the binders at $-1^{\circ} \mathrm{C}$.

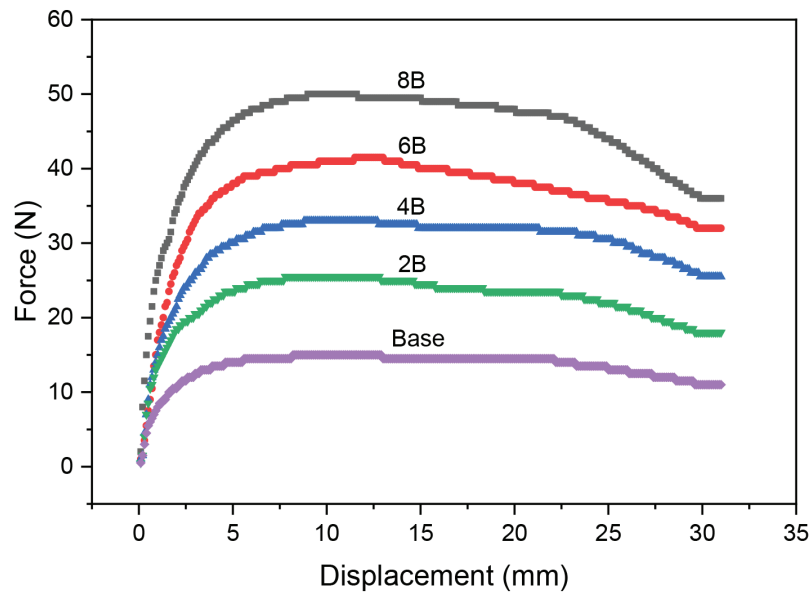

Fig. 7 Force-displacement relation of the binders at $-3^{\circ} \mathrm{C}$.

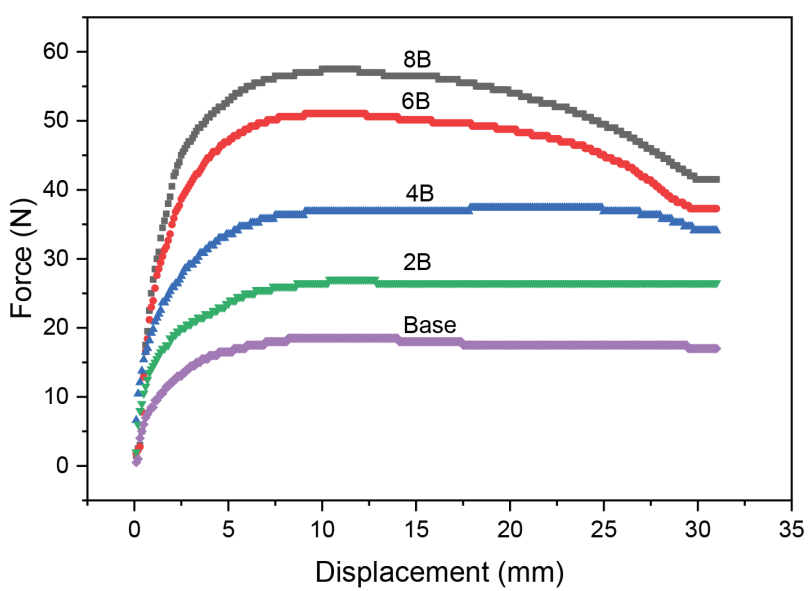

Fig. 8 Force-displacement relation of the binders at $-5^{\circ} \mathrm{C}$.

the maximum point in the load-displacement curve. However, it was determined that the $8 \mathrm{~B}$ binder returned after the peak point even at the temperature of $-5^{\circ} \mathrm{C}$ at a tensile speed of $5 \mathrm{~mm} / \mathrm{min}$. Therefore, the tensile speed of $5 \mathrm{~mm} / \mathrm{min}$ was selected for the experiments.

The force-displacement relationship of the binders is given in Figs. 6,7 and 8 together with $-1{ }^{\circ} \mathrm{C},-3^{\circ} \mathrm{C}$, and $-5^{\circ} \mathrm{C}$, respectively. The binders can bear a deformation of $30 \mathrm{~mm}$ before breaking and give a peak point. All of the binders have a maximum load value at about a
$10 \mathrm{~mm}$ displacement level. After the maximum load, the decrease in the load does not occur quickly, but the samples carry the load for a long time. The load discharge becomes apparent after a displacement of $25 \mathrm{~mm}$. The load release is faster on the $8 \mathrm{~B}$. When the temperature decreases from $-1{ }^{\circ} \mathrm{C}$ to $-5^{\circ} \mathrm{C}$, the maximum load value of the pure binder increases by $71 \%$. This increase is $66 \%, 30 \%, 39 \%$, and $19 \%$ with the $2 \mathrm{~B}, 4 \mathrm{~B}, 6 \mathrm{~B}$, and $8 \mathrm{~B}$, respectively. The sensitivity to temperature changes decreases as the SBS content increases.

Figs. 9 and 10 show the variations of the maximum load values of the SBS-modified binder at different temperatures. A decrease in temperature increases the maximum load values linearly. There is a linear relationship between the SBS content and the maximum load at the three temperatures.

Since the binders gave different maximum load values and had different load discharge tendencies, the areas under the load-displacement curves were calculated to evaluate the low-temperature performance of the binders. This area represents the absorbed energy under tension until a $30 \mathrm{~mm}$ deformation. Fig. 11 shows the changes in the areas according to the SBS content. There is a linear relationship between the SBS content and the calculated areas at all the temperatures. Increasing the SBS content requires more energy for a fracture. The $8 \mathrm{~B}$ binder can store 4 times more energy before failure than a pure binder.

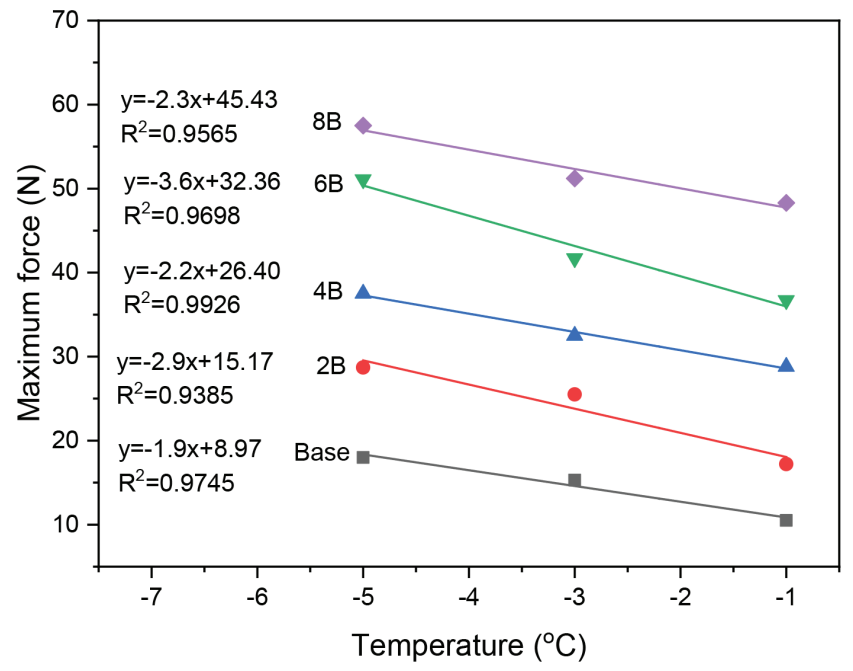

Fig. 9 Temperature - maximum force relation.

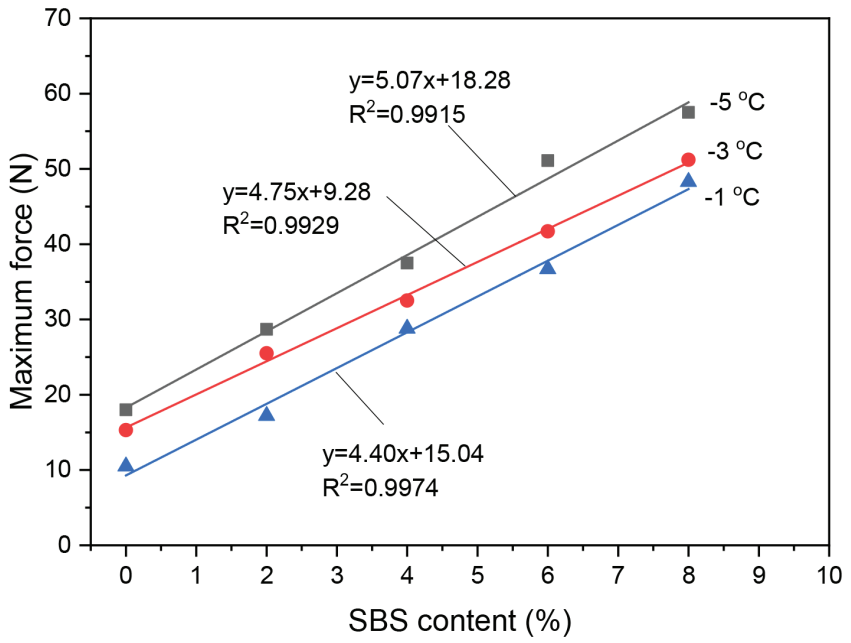

Fig. 10 SBS content - maximum force relation. 


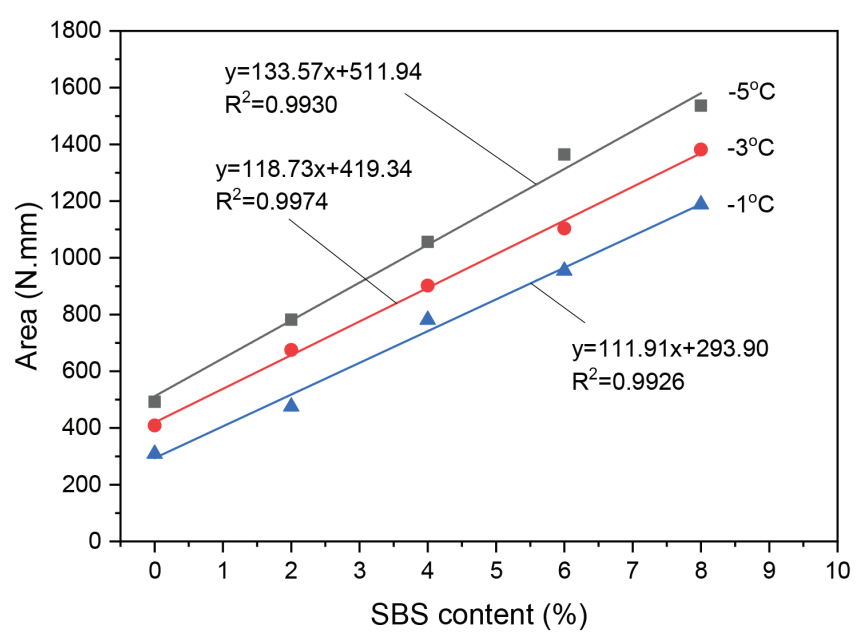

Fig. 11 Area until 30 mm elongation - SBS content relation.

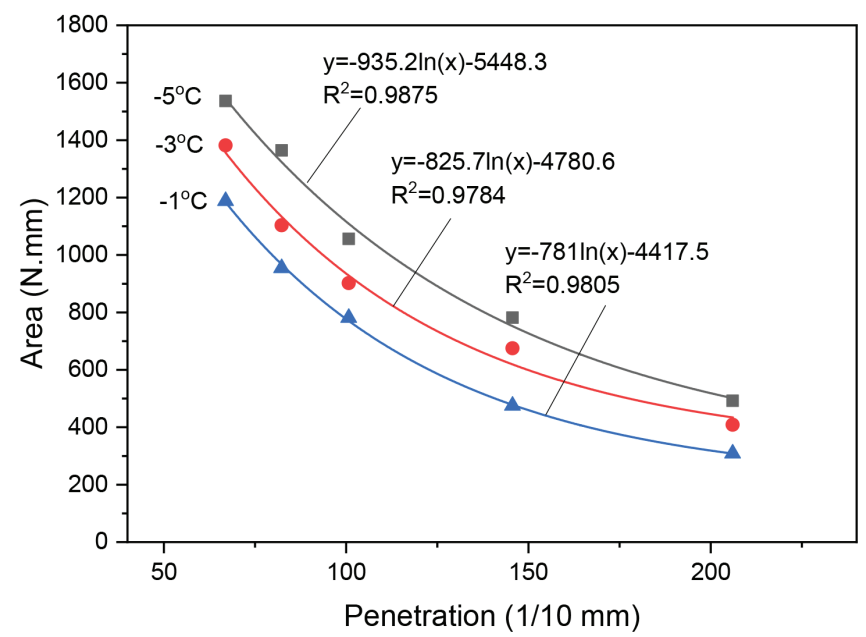

Fig. 13 Area value - penetration relation.

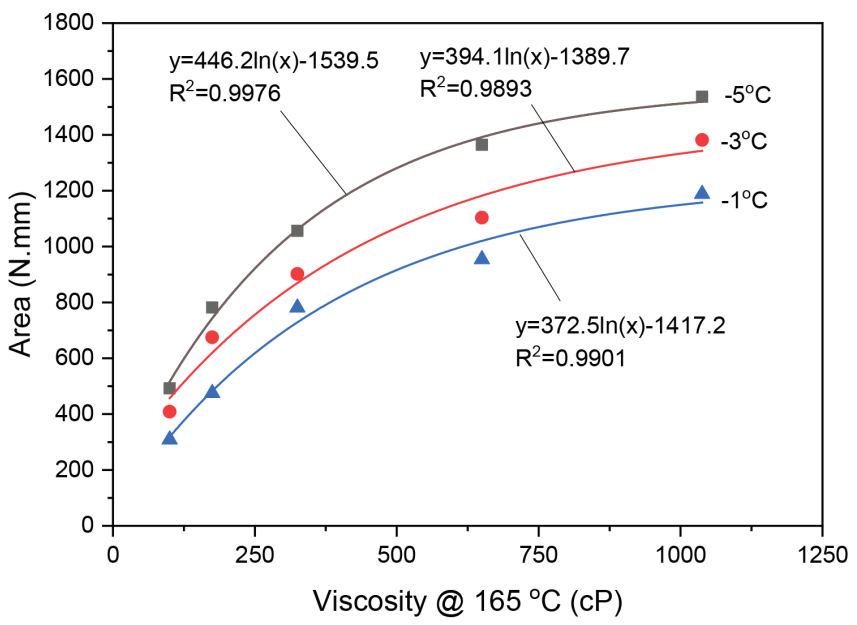

Fig. 15 Area value - viscosity at $165^{\circ} \mathrm{C}$ relation.

\subsection{Correlation Between the Low-Temperature Tensile Test and Other Binder Tests}

The compatibility of the low-temperature tensile test with conventional and rheological binder experiments was investigated. The correlation between the areas under load-displacement curves until

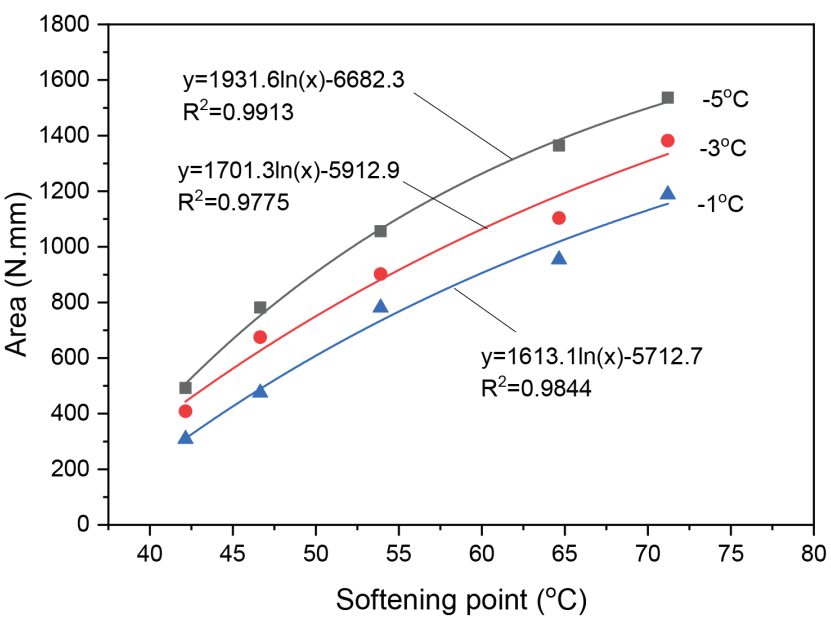

Fig. 12 Area value - softening point relation.

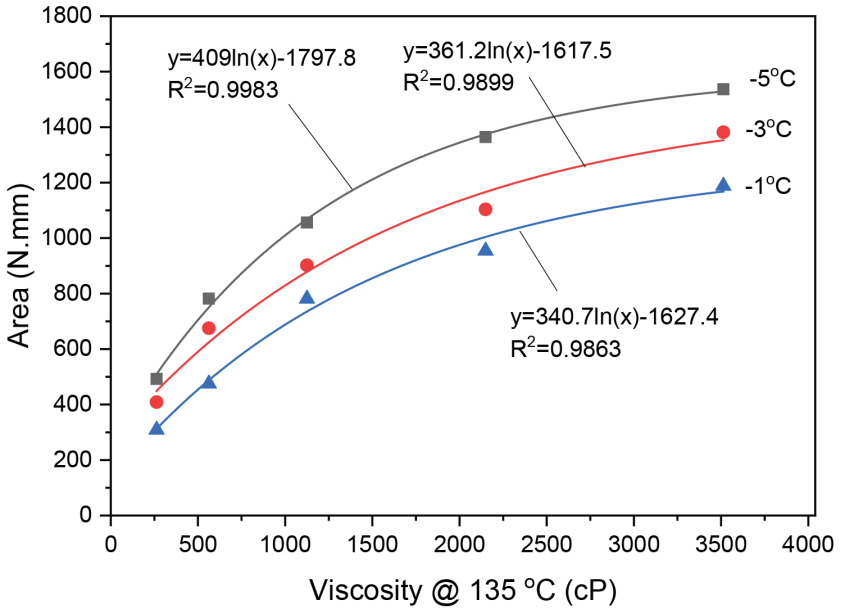

Fig. 14 Area value - viscosity at $135^{\circ} \mathrm{C}$ relation.

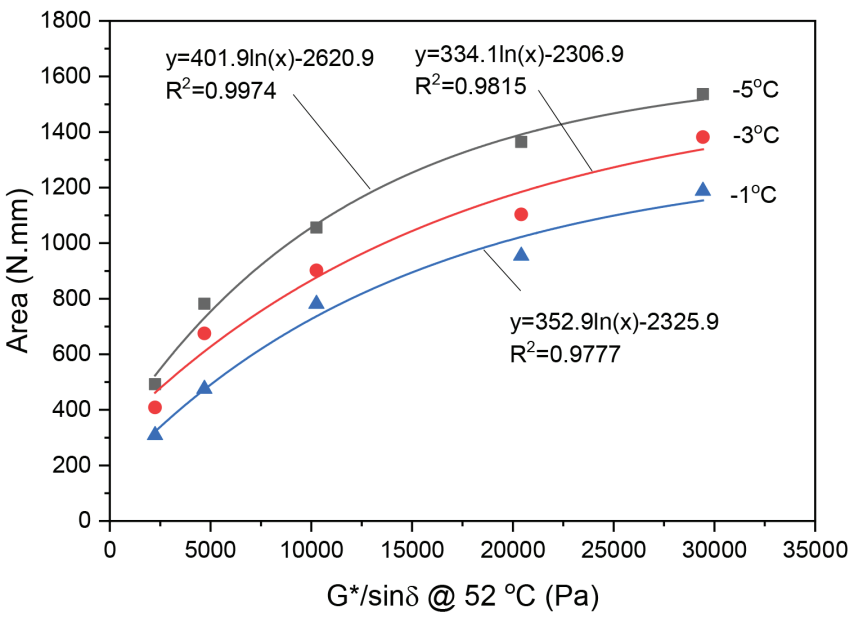

Fig. 15 Area value - viscosity at $165^{\circ} \mathrm{C}$ relation.

the $30 \mathrm{~mm}$ displacement at the tensile test and softening point values are given in Fig.12. There is a logarithmic correlation between these two tests.

The correlations between the areas and penetration values are given in Fig. 13. Fig. 13, indicates there also seems to be a logarithmic correlation between the tests. Figs. 14 and 15 show the cor- 


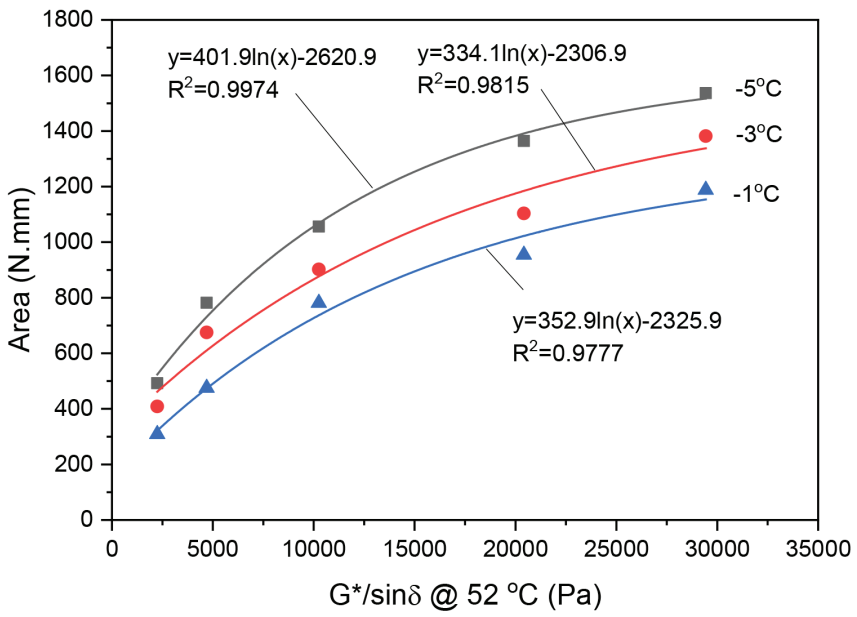

Fig. 16 Area value $-G^{*} / \sin \delta$ at $52^{\circ} \mathrm{C}$ relation.

relation between the viscosity and areas. There is a logarithmic correlation at both viscosity temperatures. Fig. 16 shows the correlation between the areas and rutting parameters to be determined at $52^{\circ} \mathrm{C}$. Here again, it is observed that there is a logarithmic correlation between the two features. Fig. 17 shows that there is a linear correlation between the areas determined by the low-temperature tensile test and $\mathrm{St} / \mathrm{m}$-value determined by the BBR test.

The areas under the load-displacement curves until the displacement level of $30 \mathrm{~mm}$ at $-1^{\circ} \mathrm{C},-3^{\circ} \mathrm{C}$, and $-5^{\circ} \mathrm{C}$ were determined to be highly consistent with other conventional and rheological tests.

\section{CONCLUSIONS}

The effect of the SBS on the conventional and rheological properties of bitumen was examined in the present study. Moreover, the cohesive property of the binders was investigated using a low-temperature tensile evaluation. Penetration, softening point, rotational viscometer, dynamic shear rheometer, and bending beam rheometer tests were applied to the base and modified binders with SBS at four different ratios of the weight of the bitumen. Afterwards, the cohesive properties of the binders were determined by applying the low-temperature tensile test. The results obtained are given below:

The addition of SBS in the pure bitumen reduced the penetration values of the binders. The softening point values increased with the addition of the SBS, and this increase was $30^{\circ} \mathrm{C}$ for the $8 \%$ SBS-modified binder. It was found that an SBS addition over $4 \%$ in the pure bitumen significantly reduced the temperature susceptibility of the bitumen. The PI values of the $6 \%$ and $8 \%$ SBS-modified binders were close to each other. The viscosity values increased exponentially with the increase in the additive content. According to the DSR test results, the rutting parameters increased exponentially with the increase in the SBS content. Furthermore, according to the BBR test results, the deformations decreased and the stiffness increased with the increase in the SBS content. Considering its temperature susceptibility, low and high-temperature performances, as well as the economic aspects, an SBS modification up to $6 \%$ can be useful as an application.

A new test method was proposed to evaluate the low-temperature tensile properties. It was determined that a tensile speed of $5 \mathrm{~mm} /$ min and test temperature of $-5^{\circ} \mathrm{C}$ were suitable for assessing highly SBS-modified binders. The binders were able to sustain a $30 \mathrm{~mm}$ displacement before rupture and gave a peak point in this test.

In general, the sensitivity to changes in temperature reduces as the SBS content increases. The SBS modification provides a good

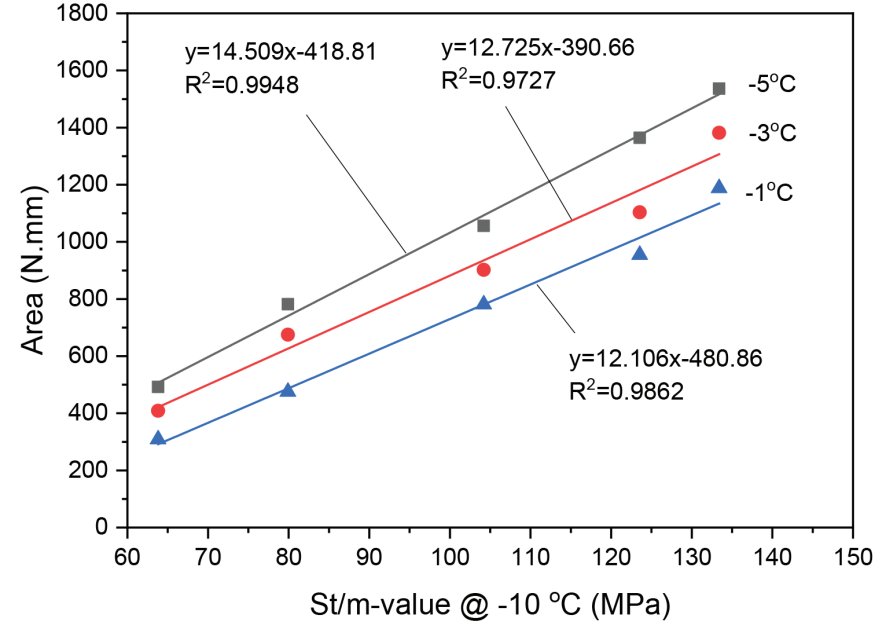

Fig. 17 Area value - St/m-value relation at $-10^{\circ} \mathrm{C}$

high-temperature performance according to the softening point and DSR test. On the other hand, the SBS makes the binder more rigid at $-10^{\circ} \mathrm{C}$ according to the BBR test. The areas under the load-displacement curve determined by the new test reveal that SBS-modified binders can store a great deal of energy before failure at $-5^{\circ} \mathrm{C}$. The results of the proposed test seem to be highly consistent with the results of the conventional and rheological tests. It is concluded that this test will be useful in determining the cohesive property of the bituminous binders. 


\section{REFERENCES}

Adedeji, A. - Grünfelder, T. - Bates, F. S. - Macosko, C. W. Stroup-Gardiner, M. - Newcomb, D. E. (1996) Asphalt modified by SBS triblock copolymer: structures and properties. Polymer Engineering \& Science, vol. 36(12), pp. 1707-1723.

Aksoy, A. - Şamlioglu, K. - Tayfur, S. - Özen, H. (2005) Effects of various additives on the moisture damage sensitivity of asphalt mixtures. Construction and building materials, vol. 19(1), pp. 1118.

Azarhoosh, A. - Moghaddas Nejad, F. - Khodaii, A. (2018) Evaluation of the effect of nano-TiO2 on the adhesion between aggregate and asphalt binder in hot mix asphalt. European Journal of Environmental and Civil Engineering, vol. 22(8), pp. 946-961.

Canestrari, F. - Cardone, F. - Graziani, A. - Santagata, F. A. - Bahia, H. U. (2010) Adhesive and cohesive properties of asphalt-aggregate systems subjected to moisture damage. Road Materials and Pavement Design, vol. 11, pp. 11-32.

Cui, S. - Blackman, B. R. - Kinloch, A. J. - Taylor, A. C. (2014) Durability of asphalt mixtures: Effect of aggregate type and adhesion promoters. International Journal of Adhesion and Adhesives, vol. 54, pp. 100-111.

Guo, M. - Tan, Y. - Wang, L. - Hou, Y. (2018) A state-of-the-art review on interfacial behavior between asphalt binder and mineral aggregate. Frontiers of Structural and Civil Engineering, vol. 12(2), pp. 248-259.

Hicks, R. G. (1991) Moisture damage in asphalt concrete (Vol. 175). Transportation Research Board.

Huang, W. - Lv, Q. - Xiao, F. (2016) Investigation of using binder bond strength test to evaluate adhesion and self-healing properties of modified asphalt binders. Construction and Building Materials, vol. 113, pp. 49-56.

Komačka, J. - Remišová, E. (2019) Investigation of the Relation between Adhesion and Water Sensitivity Test Results. Slovak Journal of Civil Engineering, vol. 27(4), pp. 1-6.

Liu, S. - Cao, W. - Fang, J. - Shang, S. (2009) Variance analysis and performance evaluation of different crumb rubber modified (CRM) asphalt. Construction and Building Materials, vol. 23(7), pp. 2701-2708.

Lu, X. - Isacsson, U. - Ekblad, J. (2003) Influence of polymer modification on low temperature behaviour of bituminous binders and mixtures. Materials and Structures, vol. 36(10), pp. 652-656.

Maliar, V. (2016) Cohesion Properties of Bitumen of Different Structures. Procedia Engineering, vol. 134, pp. 121-127.
Marasteanu, M. O. - Li, X. - Clyne, T. R. - Voller, V. - Timm, D. H. - Newcomb, D. (2004) Low temperature cracking of asphalt concrete pavement.

Oliviero Rossi, C. - Teltayev, B. - Angelico, R. (2017) Adhesion promoters in bituminous road materials: A review. Applied Sciences, vol. 7(5), pp. 524.

Omar, H. A. - Yusoff, N. I. M. - Sajuri, Z. - Ceylan, H. - Jakarni, F. M. - Ismail, A. (2016) Determining the effects of aging on halloysite nano-tube modified binders through the pull-off test meth$o d$. Construction and Building Materials, vol. 126, pp. 245-252.

Paliukaitė, M. - Vorobjovas, V. - Bulevičius, M. - Andrejevas, V. (2016) Evaluation of different test methods for bitumen adhesion properties. Transportation Research Procedia, vol. 14, pp. 724731.

Polacco, G. - Biondi, D. - Stastna, J. - Vlachovicova, Z. - Zanzotto, L. (2004) Effect of SBS on rheological properties of different base asphalts. In Macromolecular Symposia (Vol. 218, No. 1, pp. 333342). Weinheim: WILEY-VCH Verlag.

Syroezhko, A. M. - Baranov, M. A. - Ivanov, S. N. - Maidanova, N. V. (2011) Influence of natural additives and those synthesized by the Fischer-Tropsch method on the properties of petroleum bitumen and quality of floated asphalt. Coke and Chemistry, vol. 54(1), pp. 26-31.

Tarefder, R. A. - Zaman, A. M. (2010) Nanoscale evaluation of moisture damage in polymer modified asphalts. Journal of Materials in Civil Engineering, vol. 22(7), pp. 714-725.

Wei, Y. - Guo, R. - Yan, F. - Zhang, L. - Yan, Y. (2015) Evaluation of low temperature performances of SBS + PPA compound modifying asphalt by force ductility test. In: First International Conference on Information Sciences, Machinery, Materials and Energy (pp. 1897-1900). Atlantis Press.

Wistuba, M. P. - Grothe, H. - Grönniger, J. - Handle, F. (2012) Adhesion of bitumen: Screening and evaluating laboratory testing techniques. In: Proceedings of 5th Eurasphalt \& Eurobitume Congress, Istanbul, Turkey (pp. 13-15).

Zhang, H. L. - Su, M. M. - Zhao, S. F. - Zhang, Y. P. - Zhang, Z. P. (2016) High and low temperature properties of nano-particles/ polymer modified asphalt. Construction and Building Materials, vol. 114, pp. 323-332.

Zolotaryov, V. - Pyrig, Y. - Galkin, A. - Maliar, V. - Vyrozhemskyj, V. (2016) Cohesion of bituminous binders and asphalt concrete strength in shear. In: Proceedings of 6th Eurasphalt \& Eurobitume Congress, Prague, Czech Republic. 